\title{
FIO, LA FERÍA INTERNACIONAL DE TURISMO ORNITOLÓGICO
}

\author{
Juan Carlos GUERRA VELASCO \\ Departamento de Geografía. Universidad de Valladolid
}

Monfragüe es, junto con otros selectos enclaves españoles, un lugar de visita obligada para todo observador de aves. La presencia de personas pacíficamente armadas de prismáticos, trípodes y telescopios es habitual en este espacio desde bastante antes de que su declaración como parque nacional, en el año 2007, le diese la proyección pública que tiene hoy en día.

Desde los años 1980 hasta la actualidad, el pequeño núcleo de Villarreal de San Carlos ha mudado gran parte de su aspecto. La acampada, acotada a unas campas determinadas, hace tiempo que dejó de estar permitida, y en su lugar han aparecido alojamientos de turismo rural y un cercano camping. Los dos pequeños bares, de los cuales sólo uno servía una modesta comida, se han transformado en un moderno restaurante y en una tienda de recuerdos; y a ellos se les han sumado otras iniciativas relacionadas con la artesanía, el turismo activo y una parte de los edificios de la administración del parque y de sus equipamientos interpretativos.

En estos treinta años, a aquellos visitantes pioneros, en gran parte extranjeros, que buscaban emociones intensas desde un punto de vista ornitológico, se les han sumado no sólo muchas más personas intentando encontrar lo mismo, sino también miles de ocasionales turistas atraídos por la fama de Monfragüe, cimentada en la facilidad con la que se observan grandes rapaces en puntos como El Salto del Gitano y Peñafalcón, La Portilla del Tiétar o el Castillo de Monfragüe. La afluencia de público ha reducido la calidad de la visita a este espacio, pero ejemplifica perfectamente la difusión de nuevas formas de turismo, especialmente de naturaleza, a la vez que ayuda a comprender las características que poseen los nuevos nichos de mercado que se han abierto.

Dentro de este contexto, a Monfragüe se le ha añadido desde el año 2006 una iniciativa más: la celebración anual de la Feria Internacional de Turismo 
Ornitológico (FIO), organizada por la Junta de Extremadura. En este evento se conjugan las características y formatos de una feria profesional de turismo con los de las populares birdwatching fair inglesas e incluso con los rasgos de una feria de carácter comarcal. La FIO pretende, y en parte quizá lo haya conseguido, mostrar el potencial económico del turismo ornitológico, constituirse en un punto de encuentro interprofesional y comercial que acerque entre sí a los distintos "ecosistemas" empresariales que dan soporte a esta actividad y, por último, explorar la función pedagógica y de sensibilización ambiental entre el gran público que puede poseer un evento de este tipo.

Si la afluencia de visitantes con el tiempo ha transformado el núcleo de Villarreal de San Carlos, la buena acogida también lo ha hecho con la FIO. En sus siete años de vida, la feria ha incrementado su superficie, el número y perfil de los expositores, el programa de actividades que desarrolla en los tres días que dura y la afluencia de visitantes. Hasta la presente edición, en parte zarandeada por los efectos de la crisis económica, el número de expositores superaba el centenar, repartidos en tres grandes carpas con contenido temático diferenciado:

Un espacio expositivo dedicado a la óptica para la observación y fotografía de aves, librería especializada y ropa y complementos de naturaleza.

$\checkmark$ Una carpa dedicada a viaje y turismo, instituciones no extremeñas, arte y fotografía, organizaciones conservacionistas y empresas forestales y medioambientales.

$\checkmark$ Una tercera carpa reservada para las instituciones extremeñas.

Por su parte, el número de visitantes, aunque este año se ha reducido, se sitúa en torno a los quince mil, si bien en una proporción importante se corresponden con usuarios ocasionales de bienes y servicios relacionados con el turismo ornitológico o con personas simplemente atraídos por el reclamo lúdico que supone la feria. Por último, la FIO ha añadido a su oferta otras actividades, unas con un carácter central y otras de tipo complementario: conferencias sobre conservación de aves, presentaciones de paquetes turísticos, puestos de observación, guías turísticos y recorridos personalizados, concursos de fotografía, etc.

La FIO es el resultado de múltiples factores. En primer lugar, el hecho de que la España mediterránea, la más singular para un birdwatcher europeo, recibe un flujo continuado de visitantes extranjeros con un poder adquisitivo elevado en busca de determinadas aves ausentes o de difícil observación en el resto de Europa. En segundo lugar, que los españoles con la misma afición han pasado en las últimas décadas de constituir una relativa rareza a formar 
una minoría numerosa, a lo cual ha contribuido el desarrollo de la fotografía digital y su aplicación a la observación de aves (digiscoping). En tercer lugar, que también ha aumentado, en una proporción aún mucho mayor, el turista de naturaleza y más aún el que consume clorofila de forma ocasional y busca un contacto rápido, aunque en ocasiones superficial y banal, con determinados escenarios y experiencias naturales en nuestro país. Por último, el indudable desarrollo y consolidación de nuevos modelos de turismo como el de interior y el rural. Es decir, que la FIO va a satisfacer la necesidad de la existencia de un marco específico, un formato en el que visualizar y articular un mercado emergente, un nuevo negocio turístico.

Si la FIO ha sido posible por la existencia de una masa crítica previa, tampoco se puede negar que ha tenido un efecto de arrastre en este nicho turístico. Quizá sea un tanto osado señalar que en la experiencia de esta feria está directamente el origen de determinadas iniciativas o programas relacionados con el turismo ornitológico, pero lo que sí parece difícilmente discutible es que ha servido de estímulo para que tanto unos como otros hayan aparecido. El servir de punto de encuentro, de lugar en el que empezar a tejer sinergias, ha permitido, por ejemplo, la constitución de redes autonómicas de empresas de turismo ornitológico, como la castellano-manchega, o sentar las bases para un proyecto más ambicioso como es la creación de una red española con el mismo contenido temático (RETO o Red Española de Turismo Ornitológico). Por otro lado, el ser un escaparate, un lugar en el que mirar y también mostrarse ha favorecido la incorporación y reproducción por el conjunto de España de elementos novedosos. Son, por ejemplo, los cada vez más abundantes establecimientos que ofrecen lo ornitológico como elemento que define una oferta diferenciada, de calidad y comprometida con el territorio; a su vez, comienzan a ser habituales las campañas de promoción turística de carácter municipal, comarcal o provincial en las que la observación de aves aparece como un argumento destacado; se ha multiplicado la construcción de pequeños equipamientos de observación, paneles interpretativos e itinerarios guiados $\mathrm{y}$, por último, han aparecido grandes programas de carácter institucional financiados por las administraciones autonómicas que giran en torno a la difusión del turismo ornitológico.

Es el caso, entre otros de Birding Navarra, Birding in Extremadura o el programa TRINO (Turismo Rural de Interior y Ornitología) en Castilla y León. En su desarrollo responden a distintas concepciones. Algunos de estos programas tienen son "pasivos", pues sólo ponen a disposición del usuario una relación de itinerarios y alojamientos; otros giran en torno a lo que se ha denominado clubes de oferta y, por último, algunos, como es el caso de Castilla y León, desarrollan también actividades directas de observación con- 
forme a un listado de áreas de interés con el objeto de promover una incipiente demanda de servicios de este tipo.

A pesar de lo que el discurso institucional señala, a la FIO, aunque es un ejemplo, todavía le falta un largo recorrido para convertirse en un referente europeo en el sector. El modelo, por exitoso y magnitud, de las birdwatching fair inglesas quizá no sea repetible. Nos separa una enorme distancia en la práctica de la observación de aves con respecto al conjunto del Reino Unido, a la vez que el volumen del negocio que allí se mueve en torno a estas actividades y las propias necesidades que un colectivo tan amplio y de extensa tradición posee en aquel país. Ello no quita para reconocer su valor, importancia y las sinergias que está abriendo. Su capacidad para renovarse resistiendo a los embates y envites de la crisis posiblemente marque si efectivamente logra convertirse en la cita obligada que pretende ser. 